\title{
Criança, Preconceito e Raça: Transformação dos Sujeitos pelo Enfrentamento das Desigualdades Raciais no Espaço Escolar
}

\author{
Child, Prejudice and Race: Transformation of The Subjects by the Confrontation \\ of the Racial Inequalities in School Space
}

Niño, Preconcepto y Raza: Transformación de Los Sujetos por el Enfrentamiento de Las Desigualdades Raciales en el Espacio Escolar

Márcia Roseane Jerônimo de Melo ${ }^{1}$

Carlos Henrique Martins de Jesus ${ }^{2}$

Maria Cristina de Campos Magano ${ }^{3}$

\section{Resumo}

Objetivo: Analisar como o enfrentamento das desigualdades raciais dentro do espaço escolar pode transformar a formação dos sujeitos, contribuindo para uma vida adulta mais harmoniosa em sociedade. Corpo do Ensaio: É preciso analisar como se dá o racismo institucional nas instituições públicas e privadas, focando no âmbito da escola, no intuito de fazer compreender que, mesmo não explícito, é um fato que ocorre comumente no ambiente escolar através de brincadeiras, de posições em eventos, tais como desfiles e apresentações. Conclusão: Constatou-se o currículo como instrumento importante de transformação dos seres humanos. É um documento que norteia as práticas educativas para discussões que tirem as

\footnotetext{
${ }^{1}$ Mestranda em Ciência da Educação, pela Universidad Autônoma Del Sur. Especialista em Educação em Direitos Humanos e Diversidade. Graduada em Pedagogia. Autor correspondente: Campus A.C. Simões. Av. Lourival Melo Mota, s/n. Tabuleiro dos Martins. CEP:57072-900, Maceió - Al. Brasil. E-mail: marciaroseane@hotmail.com

${ }^{2}$ Mestre em Sociologia pela Universidade Federal de Alagoas. Docente da Universidade Federal de Alagoas. Pesquisador na área de Relações Étnico-raciais e de Atividade Policial.

${ }^{3}$ Mestranda em Ciências da Educação. Docente da Universidade Estadual de Alagoas. Coordenadora do Curso de Radiologia Faculdade Maurício de Nassau.

Recebido: Abr/2016 - Aceito: Jul/2017.
} 
pessoas de sua área de conforto e promovam importantes reflexões, e por isto conclui-se que nele devem ser inseridas as propostas de uma Educação em Direitos Humanos.

\section{Descritores: Racismo; Currículo;} Direitos Humanos.

\section{Abstract}

Objective: To analyze how the confrontation of racial inequalities within the school space can transform the formation of subjects, contributing to a more harmonious adult life in society. Body of the Essay: It is necessary to analyze how institutional racism occurs in public and private institutions, focusing on the scope of the school, in order to understand that, even if not explicit, is a fact that occurs commonly in the school environment through play, positions in events such as parades and presentations. Conclusion: The curriculum was seen as an important instrument for the transformation of human beings. It is a document that guides the educational practices for discussions that take people out of their comfort zone and promote important reflections, and for this reason it is concluded that the proposals of a Human Rights Education should be inserted into it.

\section{Descriptores: Racism; Curriculum;} Human Rights.

\section{Resumen}

Objetivo: Analizar cómo el enfrentamiento de las desigualdades raciales dentro del espacio escolar puede transformar la formación de los sujetos, contribuyendo a una vida adulta más armoniosa en sociedad. Es necesario analizar cómo se da el racismo institucional en las instituciones públicas y privadas, enfocándose en el ámbito de la escuela, con el fin de hacer comprender que, aun no explícito, es un hecho que ocurre comúnmente en el ambiente escolar a través de juegos, posiciones en eventos, tales como desfiles y presentaciones. Conclusión: Se constató el currículo como instrumento importante de transformación de los seres humanos. Es un documento que orienta las prácticas educativas para discusiones que sacan a las personas de su área de confort y promueven importantes reflexiones, y por ello se concluye que en él deben insertarse las propuestas de una Educación en Derechos Humanos. 
Descriptores: Racismo; Curriculum;

\section{Derechos Humanos.}

\section{Introdução}

Racismo no Brasil parece uma palavra distante, pois como dizer que brasileiro é racista se somos um país com grande mistura de raças? É difícil reconhecer-se racista, mas pode-se facilmente citar situações em que o comportamento preconceituoso aparece, mesmo que velado. Segundo Schwarcz ${ }^{(1)}$, "...] estamos diante de um tipo particular de racismo, um racismo silencioso e que se esconde por trás de uma suposta garantia da universalidade e da igualdade de leis e que lança para o terreno do privado o jogo da discriminação".

Até hoje, atitudes preconceituosas e de discriminação racial são camufladas com a falsa pretensão de harmonia social através do conceito de democracia racial, que pressupõe a existência de igualdade entre negros e branco. De acordo com Gomes ${ }^{(2)}$ :

A democracia racial é uma corrente ideológica que pretende eliminar as distinções entre as 'três raças' formadoras da sociedade brasileira (a negra, a indígena e a branca), afirmando que existe entre elas união e igualdade. Elimina-se, supostamente, o conflito, continuando a perpetuar estereótipos e preconceitos, pois, se seguirmos a lógica de que todas as raças estão unidas desde o início, podemos pensar que as diferentes posições hierárquicas entre elas devem-se a uma incapacidade inerente a algumas.

Desta feita, ao negar-se a existência do racismo no Brasil, afirmase ser desnecessário criar políticas públicas para enfrentá-lo. Akkari, Marques e Santiago ${ }^{(3)}$ apontam que "a negação da existência de discriminação e desigualdade raciais oculta a hierarquização racial presente na sociedade, influenciando a aceitação e a concretização de políticas e outras medidas que visem minimizar o hiato entre a população negra e a branca".

No cotidiano das escolas, frequentemente, as questões raciais e o preconceito afloram, e as práticas baseadas no senso comum muitas vezes reforçam o racismo. É comum associar cabelo louro e olhos claros à beleza e pele negra e cabelo crespo, ao feio. Além disso, até mesmo os livros didáticos reforçam estas noções desde a educação infantil. Akkari, Marques e Santiago $^{(3)}$ abordam a questão de preconceitos étnico-raciais no currículo escolar, como podemos conferir a seguir:

[...] deparamo-nos com formas explícitas de inferiorização de negros (as) e de indígenas e de 
supervalorização de brancos (as) no currículo escolar como um todo. É possível identificarmos imagens, palavras, conceitos e atitudes que estigmatizam negros (as) e indígenas. $^{(3)}$.

O negro e o preconceito andam juntos no espaço escolar. Não se costuma atentar para o fato de que as condições históricas de inserção social, somadas às condições de localização geográfica da moradia, baixa renda e autoconceito negativo são fatores que determinam a falta de acesso a bens e serviços dentro da sociedade. Junto a isso, a determinação social da criança afeta diretamente seu comportamento e rendimento escolar.

$$
\text { Infelizmente, as práticas }
$$
discriminatórias são um evento em escala que começam nas relações interpessoais familiares, na formação de círculos sociais, e atingem instituições como a escola, com base em pressupostos sociais enraizados na dominação, dificultando e, muitas vezes, até impedindo o acesso a bens e direitos sociais. Isso é reproduzido dentro da escola como um caminho natural sem qualquer reflexão ou questionamento, compatível com o que afirmam Bourdieu e Passeron ${ }^{(4)}$, quando afirmam que a violência simbólica tenta desvendar o mecanismo que faz com que os indivíduos vejam como "naturais" as representações ou as ideias sociais dominantes.

Quijano $^{(5)}$ demonstra que a ideia de raça só surgiu nas Américas, inexistindo antes do descobrimento do novo mundo, pois a ideia de raça estava diretamente relacionada às diferenças fenotípicas entre os descobridores e a população local. Segundo o autor, a formação das relações sociais fundadas na ideia de raça produziu nas Américas novas identidades sociais - índios, negros, mestiços.

$\mathrm{O}$ preconceito racial e os estereótipos experimentados pelas crianças negras em sua convivência no espaço escolar e social influenciam o seu desenvolvimento como um todo, induzindo-as à baixa autoestima. É importantíssimo ressaltar que as questões raciais e o preconceito são nitidamente percebidos e vividos pelas crianças negras no cotidiano dos estabelecimentos de ensino, no convívio com as outras crianças e com os adultos.

Desta forma, Akkari, Marques e Santiago $^{(3)}$ afirmam que:

\footnotetext{
O espaço escolar tem sido ponto de partida para a compreensão das disparidades raciais à medida que alguns pesquisadores destacam seu papel na difusão do preconceito e da discriminação, legitimando assim a histórica assimetria entre negros e brancos em seus múltiplos aspectos ${ }^{(3)}$.
} 
Mesmo após a criação da Lei $10.639 / 03$, que garante o ensino da cultura afro-brasileira e da história da África nos estabelecimentos de ensino fundamental e médio, com o objetivo claro de romper a intolerância racial e valorizar a participação dos negros na constituição da população brasileira, observa-se que esta ação ainda é praticada de forma superficial e que o preconceito aparece de forma mascarada nos comportamentos e ações dentro do ambiente escolar.

A diversidade racial brasileira revela a riqueza de um povo que se miscigenou ao longo de sua história e precisa aprender a conviver com a grande variedade de raças que entraram em sua composição, tendo o negro contribuído em grande número, pois foram "[...] 3,6 milhões de africanos trazidos compulsoriamente: um terço da população africana que deixou seu continente de origem rumo às Américas"(1).

Entretanto, o emblema eurocêntrico é tão fortemente impresso que nem mesmo a Lei 10.639/03 tem conseguido incluir a história real de resistência e conquistas dos povos negros ao longo de séculos de história nos Projetos Políticos-Pedagógicos e nas práticas cotidianas das escolas.
Gomes $^{(6)}$ acredita que esta lei, ao modificar os artigos 26-A e 79-B da Lei de Diretrizes e Bases da Educação Nacional, deu partida nas discussões sobre diversidade racial dentro e fora da escola. Para Gomes ${ }^{(6)}$ :

$$
\begin{aligned}
& \text { É possível perceber que o Estado } \\
& \text { brasileiro, ao reconhecer a } \\
& \text { imbricação entre desigualdades e } \\
& \text { diversidade, vem incorporando, aos } \\
& \text { poucos, a raça de forma } \\
& \text { ressignificada em algumas de suas } \\
& \text { ações e políticas, especialmente na } \\
& \text { educação. [...] é possível afirmar que } \\
& \text { a sociedade brasileira não teria } \\
& \text { chegado a esse momento se não fosse } \\
& \text { a histórica atuação do movimento } \\
& \text { negro. }
\end{aligned}
$$

Torna-se, então, de fundamental importância pensar na formação docente para a infância com um currículo de valorização cultural que contemple a importância dos africanos na formação do povo brasileiro, ressignificando $\mathrm{o}$ conceito de raça negra e dando real valor à cultura africana. Dessa forma, é imprescindível a construção de um currículo baseado na valorização da diversidade étnico-racial e, nesse sentido, Aquino ${ }^{(7)}$ aponta que:

Para compreender o conjunto de Saberes dos professores da educação infantil, é preciso considerar as marcas produzidas historicamente em sua trajetória profissional, marcadas pela diversidade de funções do atendimento às crianças pequenas que refletem e influenciam o cotidiano da educação infantil. 
Superar as manifestações de discriminação, preconceito $\mathrm{e}$ iniquidades diversas é condição sine qua non para que seja implementada a transversalização da temática do negro no currículo escolar, da educação infantil até à universidade, pois não podemos mais invisibilizar as raças que tanta importância tiveram na construção sociopolítica e econômica do Brasil. Ainda, conforme Onofre ${ }^{(8)}$, a educação precisa ter como proposta de trabalho "[...] a eliminação de qualquer tipo de discriminação por parte de educadores e educandos nos espaços escolares".

Diante do exposto, este artigo tem como principal objetivo analisar como $\mathrm{o}$ enfrentamento das desigualdades raciais dentro do espaço escolar pode transformar a formação dos sujeitos.

\section{O racismo institucional praticado na escola}

Pode-se falar de diversos tipos de racismo: racismo interpessoal, racismo institucional, racismo introjetado, entre outros, mas em todos estes tipos, podese perceber que o racismo é uma forma de pensamento responsável pela criação de mitos que subjugam o "outro" a um lugar inferior. Ninguém pode ser menosprezado pela cor de sua pele, pois uma pessoa não tem a opção de mudar a cor da sua pele. Um ser humano não pode ser descrito como inferior porque tem a pele negra. Schwarcz ${ }^{(1)}$ explica melhor o racismo estabelecido no Brasil:

$$
\begin{aligned}
& \text { O relato de Nabuco, na verdade, } \\
& \text { retoma e atualiza uma linha de } \\
& \text { pensamento, uma família } \\
& \text { interpretativa que aposta no lado } \\
& \text { integrativo do modelo brasileiro [...] } \\
& \text { de convivência racial. Coloca ainda } \\
& \text { um tijolo de teoria nessa espécie de } \\
& \text { racismo à brasileira: um racismo que } \\
& \text { é sempre jogado para o "outro". O } \\
& \text { outro da história, o outro que não sou } \\
& \text { "eu": o proprietário de escravos } \\
& {[\ldots]^{(1)} \text {. }}
\end{aligned}
$$

O racismo institucional surge na escola, por exemplo, quando uma menina negra é impedida de ser a rainha do milho na quadrilha porque, ao invés de escolhê-la, as outras crianças votam na menina loira dos olhos claros. Então, percebe-se que o racismo está impregnado no subconsciente das pessoas e a escola precisa trabalhar esse preconceito.

Destarte, o racismo institucional pode ser definido como:

[...] o fracasso das instituições e organizações em prover um serviço profissional e adequado às pessoas em virtude de sua cor, cultura, origem racial ou étnica. Ele se manifesta em normas, práticas e comportamentos discriminatórios adotados no cotidiano do trabalho, os quais são resultantes do preconceito racial, uma atitude que combina estereótipos 
racistas, falta de atenção e ignorância. Em qualquer caso, o racismo institucional sempre coloca pessoas de grupos raciais ou étnicos discriminados em situação de desvantagem no acesso a benefícios gerados pelo Estado e por demais instituições e organizações ${ }^{(9)}$.

O racismo institucional é responsável pelo tratamento diferenciado entre negros e brancos dentro das instituições públicas e privadas, manifestando-se por preconceitos e ações discriminatórias. $\mathrm{Na}$ tentativa de superar essas desigualdades, em abril de 2012, o Supremo Tribunal Federal considerou, por unanimidade, a constitucionalidade da política de cotas étnico racial para seleção de estudantes nas universidades. $\mathrm{O}$ fato de a população negra vivenciar relações sociais discriminatórias faz com que a sociedade (negros ou não) receba informações preconceituosas através dos meios de comunicação em espaços como a escola, o clube e nas relações interpessoais. Este fato cria um sentimento de inferioridade na criança negra dentro e fora do ambiente escolar, que relembra as práticas escravocratas de infantilização, inferiorização e invisibilidade da raça negra.

\section{A importância de um currículo que afirme a diversidade, desconstruindo o preconceito racial}

Sabendo-se que o currículo é o norteador das práticas docentes, este não pode ser estático, mas sim reformulado na medida que se exige a condição humana a cada época. O currículo deve levar em conta o contexto do espaço onde vai ser executado, mas não pode se limitar à vivência de cada ser que faz parte dessa comunidade escolar, precisa ser ampliado. É necessária a inserção de novos conhecimentos que preparem o sujeito para a convivência com a diversidade. Esta é uma das possibilidades de destravar as visões estagnadas e radicais que são construídas historicamente em toda cultura, levando em consideração que a diversidade é intrínseca à vida humana. Como afirma Onofre ${ }^{(8)}$.

[...] a diversidade é característica da espécie humana nos saberes, modos de vida, culturas, personalidades, meios de perceber o mundo, o currículo precisa priorizar essa universalidade. A instituição escolar não pode isentar-se do seu compromisso enquanto propiciadora de formas acolhedoras da diversidade.

As crianças, quando chegam à escola, não são como folhas em branco, pois já trazem consigo tudo o que foi aprendido dentro de seu contexto familiar e social. Desta forma, ao entrarem em contato com os conteúdos 
abordados na escola, poderão reafirmar (pre)conceitos ou modificá-los através da reflexão, e é daí que surge a importância da construção de um currículo abrangente e multifacetado que não restrinja $\mathrm{o}$ pensamento $\mathrm{e} a$ aceitação da diferença. A própria sociedade pode pressionar a escola a atualizar os conteúdos do currículo, estimulando-a a mudanças no sistema educativo. Como Sacristán ${ }^{(10)}$ tão bem enfatiza, a escola muda "como reflexo da pressão que a instituição escolar sofre desde diversas frentes, para que adapte seus conteúdos à própria evolução cultural e econômica da sociedade".

A escola não pode fugir à responsabilidade de acolher a diversidade. Precisa se preparar para essa discussão, tomá-la como incumbência e levá-la para o interior do currículo, promovendo um debate para todos. Os conteúdos escolhidos para a construção do currículo devem contemplar a formação do indivíduo para a alteridade e a empatia, de forma que sejam internalizadas para a vida adulta, pois alicerçar esse aprendizado não é algo simples, uma vez que envolve vários âmbitos como família, escola e sociedade.
O currículo pode, então, ser visto como um importante instrumento de transformação dos seres humanos, uma vez que sua abordagem pode levar a discussões que tiram as pessoas de sua zona de conforto e promovem importantes reflexões. É fundamental pensar sobre a construção social da raça "[...] considerando-a como estrutural e estruturante na formação da América Latina", como tão bem enfatiza Gomes $^{(6)}$.

Segundo Onofre ${ }^{(8)}$, "refletir sobre o currículo perpassa questões tão importantes quanto imprescindíveis para uma análise dos aspectos subjetivos referentes à concepção de currículo que temos construído ao longo da história da educação brasileira". Assim sendo, faz-se necessário utilizar o currículo como importante ferramenta de conhecimento das diferentes nuances da diversidade cultural e étnica, pressupondo o estabelecimento de novos paradigmas na educação ${ }^{(8)}$.

Desta forma, o desenvolvimento da educação em direitos humanos, no Brasil e em outros países, é um processo que emergiu com força total na segunda metade dos anos 80, no bojo dos processos de democratização vividos por várias nações. Com as violações dos direitos humanos, fortaleceu-se a 
consciência da necessidade de promover processos sociais, políticos e educacionais que propiciem a internalização dos direitos humanos e da dignidade do ser humano por parte dos cidadãos e do imaginário coletivo.

São imprescindíveis ações e processos orientados para a prevenção e a afirmação dos direitos humanos em todos os âmbitos da sociedade, da família e das políticas públicas. É nessa perspectiva que se situa a educação em direitos humanos, que se propõe a estimular os livros didáticos a enfatizarem a história e a participação da população negra na construção do país, com o objetivo de abrir novos caminhos, tanto nos espaços de educação escolar, como de educação não formal, propiciando oportunidades para a formação de novos sujeitos.

\section{O surgimento dos direitos humanos e sua relação com a superação das desigualdades}

O termo Direitos Humanos, atualmente tema de grandes debates, exige de todos nós um aprofundamento teórico no sentido de problematizar e questionar visões - compartilhadas e profundamente enraizadas no senso comum - que desvirtuam a proposta de universalidade dos direitos contida na Declaração Universal dos Direitos Humanos (1948), que significa que todas as pessoas, independente de classe social, cor, raça e etnia, são sujeitos de direitos $^{(11)}$. Mais profundamente pensa Dallari $^{(12)}$, quando diz que a vida é um direito humano e que sem ela a pessoa não existe; que preservar na vida é uma necessidade das pessoas humanas. Por esse prisma, preservar a vida depende da garantia de alguns elementos indispensáveis, como a alimentação, a saúde, a moradia e a educação, conhecidos como os direitos fundamentais.

É muito comum ouvir discursos que se opõem a esta perspectiva e que trazem para o centro do debate a universalidade dos direitos, isentando o Estado e os mais privilegiados socioeconomicamente de toda e qualquer responsabilidade sobre os mecanismos que originam e reforçam todo tipo de exclusão e opressão. Desta forma, tenta-se argumentar sobre a necessidade de cotidianizar a ideia dos direitos como forma de garantir uma sociedade menos desigual e mais justa. Discutir coletivamente sobre o tema dos direitos humanos no campo da educação se faz, então, pertinente. 
Pode-se iniciar o processo de qualificação do termo afirmando a ideia de que o discurso sobre os direitos humanos deve se pautar na visão de que eles devem se contrapor a qualquer forma de descumprimento dos direitos inerentes a uma vida digna. Segundo Sarmento $^{(13)}$ :

A noção de dignidade evoluiu com o tempo. Num primeiro momento tentou-se explicá-la a partir de argumentos religiosos que defendiam a origem divina do homem, criado à imagem e semelhança de Deus. Depois a tese de que ela era inata, que integrava a essência do ser humano.

Dessa forma, como foi dito anteriormente, os Direitos Humanos devem se colocar contra toda e qualquer forma de impunidade ao desrespeito à dignidade humana. Outro ponto importante deste debate é reconhecer que todas as pessoas nascem iguais e livres. Assim, Dallari ${ }^{(12)}$ afirma que cada pessoa humana apresenta sua individualidade, seu modo peculiar de enxergar e vivenciar o mundo, e que os grupos sociais têm sua própria cultura, se assemelhando aos seres humanos em suas necessidades básicas. Daí a existência dos direitos fundamentais, que são iguais para todos os seres humanos.
Assim, é fato que os Direitos Humanos - para além da garantia de necessidades fundamentais da vida estão dimensionados para a preocupação com outras questões, tais como o racismo, a exclusão social, o trabalho infantil e educação, como também para a diversidade étnico-racial e sexual, que traz uma maior situação de vulnerabilidade.

Vale destacar que os Direitos Humanos não surgiram aleatoriamente, nem tão pouco em um só momento, mas gradativamente e de acordo com a evolução do homem, travando lutas após constatações de insatisfações e carências. Assim, segundo Sarmento ${ }^{(13)}$, "os primeiros direitos humanos surgiram da luta contra a opressão e a tirania impostas ao povo pelos governos despóticos de orientação absolutista". Sarmento ${ }^{(13)}$, ainda afirma que:

Os direitos humanos não são estanques ou incomunicáveis, mas complementares e conexos: integramse uns aos outros para realizar o ideal de dignidade humana. $\mathrm{O}$ vocábulo "geração" nos remete à ideia de direitos sob a mesma inspiração axiológica [...] e que se pode esquematizar as gerações de direitos humanos da seguinte forma: a) $1^{\mathrm{a}}$ Geração - liberdades públicas e direitos políticos; b) $2^{\mathrm{a}}$ geração direitos sociais, econômicos e culturais; c) $3^{\mathrm{a}}$ geração - direitos difusos, coletivos e individuais homogêneos; d) $4^{\text {a }}$ geração - direitos da bioética e direito da informática $^{(13)}$.

Entretanto, apesar de a Declaração

Universal dos Direitos Humanos chegar 
à marca de 60 anos de sua aprovação, ainda é fortemente evidente a intolerância frente a tudo que ela nos remete. É provável que isto aconteça pela falta de uma educação que contemple a história dos Direitos Humanos. É importante, segundo Vieira $^{(11)}$, fortalecer a gramática dos Direitos Humanos, que está fundamentada no pressuposto ético e moral de que todas as pessoas merecem igual respeito por parte das outras pessoas.

A partir dessa compreensão de igualdade e respeito entre todos, e de que todo homem e toda mulher são sujeitos de direitos, expressão fortalecida na Constituição Federal Brasileira, pode-se pensar numa sociedade, de fato, norteada pela ideia de Direitos Humanos, em que esta compreensão perpasse todos os âmbitos, pois a história dos Direitos Humanos está intimamente ligada aos movimentos sociais que lutam por democracia, liberdade e igualdade.

Seria negligente não abordar a incessante perda de valores nos dias atuais, tais como: respeito, alteridade e empatia. Talvez estas circunstâncias advenham das mazelas do capitalismo, pois como demonstra Dallari ${ }^{(12)}$, o crescimento econômico e o progresso material de um povo tem valor negativo se forem conseguidos à custa de ofensas à dignidade das pessoas.

Apesar de todas as conquistas após a promulgação da Declaração Universal dos Direitos Humanos, é possível crer que toda subjetividade que envolve os Direitos Humanos pode desencadear esta complexidade de opiniões e discursos cotidianos. Assim, não se pode descartar que a compreensão dos Direitos Humanos é a única maneira de combater a guerra nas relações humanas, ainda que subjetivas, e esta missão é incumbida à educação. Argumenta-se que é através dela que se pode garantir uma consciência social maior sobre os direitos individuais e coletivos. Faz-se necessário, ainda, abordar incessantemente a ineficiência e negligência do Estado sobre a efetivação dos direitos básicos à vida, já que esta omissão e a falta de implementação de políticas públicas são a causa de diversos problemas sociais, como a intolerância racial e o preconceito contra o negro.

Direitos humanos como forma de garantir a diversidade e a superação do racismo dentro e fora da escola

$\mathrm{O}$ grande desafio à cidadania e à democracia no Brasil consiste em se 
fazer valer os Direitos Humanos a todos, sem distinção. A superação do preconceito racial pressupõe $\mathrm{o}$ enfrentamento de tramas de sociabilidade, já tão enraizadas no imaginário social brasileiro, e o aguçamento de tensões entre polos de desigualdade e violência que acabam por aprofundar o desafio democrático. Segundo Sales ${ }^{(14)}$ :

\begin{abstract}
A justiça brasileira acaba por trazer em si as marcas de uma sociedade historicamente desigual, marcada pela experiência escravocrata. Após a libertação dos escravos, os negros não foram agraciados por qualquer política pública, que tentasse reverter $o$ processo originado durante a escravidão. $\mathrm{E}$ este fato acabou marcando nossa sociedade como um todo, pois as consequências negativas não recaíram apenas sobre os negros, mas, sobretudo, sobre a formação da cidadania brasileira, que foi cunhada principalmente pela desigualdade.
\end{abstract}

Ainda segundo o autor, "a cultura política engendrada no Brasil, da Colônia aos dias de hoje, não obstante momentos e movimentos de investimento na construção de vínculos civilizatórios tem sido [...] marcada por: discriminações sociais, étnicas $[\ldots]^{\prime(14)}$. Sendo assim, a noção de Direitos Humanos vem desconstruir as marcas das desigualdades engendradas na história da nação brasileira.

Todas as pessoas nascem essencialmente iguais e, portanto, têm direitos iguais. Assim sendo, a perpetuação dos preconceitos raciais vai de encontro com a noção de Direitos Humanos, pois é indispensável que todos tenham a mesma possibilidade de gozar dos direitos fundamentais. Desta forma, conta-se com mecanismos que comprometem o Estado e a sociedade com a efetivação da democracia e da inclusão. Sobre isso, Almeida $^{(15)}$ enfatiza que:

\begin{abstract}
A associação entre educação e Direitos Humanos, para aproximação entre conquistas formais e realidade, requer que se amplie o sentido da educação, para além da escola e do sistema de ensino formal, para alcançar múltiplas iniciativas sociais que estejam pautadas na ética do reconhecimento do outro, da inclusão e da igualdade, com valorização da diferença.
\end{abstract}

Assim, é através da educação que a população negra começa a vivenciar lentamente, nos dias atuais, depois de tantas lutas dos movimentos negros, um processo de reconhecimento e orgulho em ser negro. Processo esse que, conforme Hall $^{(16)}$, passa por questões de estética, cultura e história, haja vista que a identidade é um processo constante de construção que se estabelece dentro da sociedade, imbricada nas relações entre as pessoas. A compreensão das diversas belezas de ser negro passa, necessariamente, pela valorização da 
cultura africana como base da cultura negra estabelecida no Brasil e real reconhecimento de sua importância.

\section{Conclusão}

Ao se estabelecer um currículo escolar onde os Direitos Humanos permeiam todas as disciplinas estudadas e níveis educacionais, estaremos dando espaço à construção de novos sujeitos em nosso espaço social que são capazes de conviver com as diferenças sem estigmatizá-las, pois terão aprendido o sentido de conviver com a diversidade em harmonia. $O$ fato é que não é obrigatório ser igual, pois a diferença enriquece a convivência humana.

Sendo assim, a escola, ao despirse de (pre)conceitos, será capaz de abrir espaço para o florescimento de cada criança negra, parda, branca ou amarela, sem diferenciá-las por algo que não escolheram para suas vidas. Impõe-se à criança negra um enorme sofrimento por culpabilizá-la por algo que não se pode reverter, ou que nem mesmo foi possível escolher a priori - a cor de sua pele.

Logo, esta discussão não pode ser mantida oculta da sociedade, mas precisa iniciar no seio da escola e ultrapassar seus muros. As discussões sobre 0 enfrentamento das desigualdades não podem restringir-se aos singulares, precisam atingir a sociedade como um todo, ganhando visibilidade, sobretudo através dos movimentos negros. A população negra não é uniforme, sua cultura e organização são diversificadas, e ela deriva da luta histórica pela sobrevivência e por inserção digna na sociedade. Assim, a escola, a sociedade e o Estado não podem se isentar da construção de um mundo mais equânime, guiado pela postura ética e valorativa, diante do reconhecimento da cultura afrodescendente.

\section{Referências}

1. Schwarcz LM. Nem preto nem branco, muito pelo contrário: cor e raça na sociabilidade brasileira. São Paulo: Claro Enigma; 2012.

2. Gomes NL. Alguns termos e conceitos presentes no debate sobre relações sociais no Brasil: uma breve discussão. Ministério da Educação (Brasília) [periódico na Internet]. 2005 [citado 2016 nov. 05]; 39-62. Disponível em: http://www.acaoeducat iva.org.br/fdh/wp-content/uploads/2012/ 10/Alguns-termos-e-conceitos-presente s-no-debate-sobre-Rela $\% \mathrm{C} 3 \% \mathrm{~A} 7 \% \mathrm{C} 3 \%$ B5es-Raciais-no-Brasil-uma-breve-disc uss $\% \mathrm{C} 3 \% \mathrm{~A} 3$ o.pdf.

3. Akkari A, Marques LP, Santiago MC. Educação intercultural: desafios e possibilidades. Rio de Janeiro: Vozes; 2013; 126-7. 
4. Bourdieu P, Passeron JC. A reprodução: elementos para uma teoria do sistema de ensino. In: Bairão R., tradução. Garcia PB, Baeta AM, revisão. Rio de Janeiro: Vozes; 2009.

5. Quijano AA. Colonialidade do poder, eurocentrismo e América Latina. In: Lander E., organizador. A colonialidade do saber: eurocentrismo e ciências sociais - perspectivas latino-americanas. Buenos Aires: Clacso; 2005.

6. Gomes NL. Movimento negro e educação: ressignificando e politizando a raça. Educação e Sociedade (Campinas) [periódico na Internet]. 2012 [citado 2016 nov. 08]; 33(120): 727-44. Disponível em: http://www. scielo.br/scielo.php?pid=S0101-733020 $12000300005 \&$ script $=$ sci_abstract\&tlng $=$ pt.

7. Aquino LMMLL. Saber docente: questões para pensar prática na educação infantil. In: Vasconcellos VMR, Aquino LMMLL, Dias AA., organizadores. Psicologia e educação infantil. São Paulo: Junqueira e Marin; 2008.

8. Onofre JA. Repensando a questão curricular: caminho para uma educação antirracista. Revista Práxis Educacional, Vitória da Conquista. Educação (Bahia) [periódico na Internet]. 2008 [citado 2016 nov. 12]; 4(4): 103-22. Disponível em: http://periodicos.uesb.br/index.php/ praxis/article/view/329.

9. CRI. Articulação para o Combate ao Racismo Institucional. Identificação e abordagem do racismo institucional. Brasília: CRI; 2006.

10. Sacristán GJ. O currículo: uma reflexão sobre a prática. Porto Alegre: Artmed; 2000.
11. Vieira VO. Para conhecer os Direitos Humanos. Revista da Universidade de São Paulo (USP). 2001; 51: 210-7. Disponível em: https://www.revistas.usp.br/revusp/artic le/view/35114/37853.

12. Dallari DA. Direitos Humanos e Cidadania. Col. Polêmica. São Paulo: Moderna; 2004.

13. Sarmento G. As gerações dos direitos humanos e os desafios da efetividade; 2011. Disponível em: ht tp://www.georgesarmento.com.br/wp-.

14. Sales MA. (In)visibilidade perversa: adolescentes infratores como metáfora da violência. São Paulo: Cortez; 2007.

15. Almeida FG. Formação de educadores sociais: coletânea de textos. Salvador: Universidade Federal da Bahia, Secretaria de Trabalho e Ação Social - SETRAS; 2001.

16. Hall S. A identidade cultural na pósmodernidade. Trad. Tomaz Tadeu da Silva e Guacira Lopes Louro. Rio de Janeiro: DP \& A; 2003. 